\title{
General and domain-specific grit both show a negative association with scholastic aptitude in a large sample of university applicants
}

\author{
Štěpán Bahník* and Marek A. Vranka \\ Faculty of Business Administration, University of Economics, Prague, náměstí Winstona \\ Churchilla 4, Prague, 130 67, Czech Republic. \\ *Corresponding author. bahniks@seznam.cz
}

\begin{abstract}
Grit has been proposed as an important factor influencing success in various domains. It might therefore be used for predicting success and as a target of interventions aiming to improve achievement. The present two studies examined domain-specificity of grit and the association between grit and result in a scholastic aptitude test in large samples of university applicants (total $N=4,920$ ). Grit showed a small-to-moderate negative association with the test results. This negative association did not differ strongly between general grit and grit measured in relation to studying or hobbies. The study shows that high grit does not predict success in the standardized university admission test. Furthermore, focusing grit on the domain of interest does not improve its predictive ability.
\end{abstract}

Keywords

grit, scholastic aptitude, conscientiousness, education, intelligence, motivation

Grit, defined as "perseverance and passion for long-term goals" (Duckworth, Peterson, Matthews, \& Kelly, 2007, p. 1087), has been proposed as an important factor which might explain differences in success of otherwise similarly able individuals. For example, studies found that grit is positively associated with undergraduates' grade point average (Bowman, Hill, Denson, \& Bronkema, 2015; Duckworth et al., 2007), rankings in the spelling bee (Duckworth, Kirby, Tsukayama, Berstein, \& Ericsson, 2011; Duckworth et al., 2007), and teachers' effectiveness (Robertson-Kraft \& Duckworth, 2014). A recent meta-analysis (Credé, Tynan, \& Harms, 2017) found positive associations of grit with achievement in both academic and nonacademic domains. Yet, usefulness of the grit construct may be limited given that it is strongly correlated with a closely related conscientiousness personality trait and it does not seem to add much information for predicting academic achievement once conscientiousness is taken into account (Credé et al., 2017). Moreover, grit is traditionally thought to consist of perseverance of effort and consistency of interest facets (Duckworth et al., 2007); however, based on the metaanalysis, Credé et al. (2017) argue that combining the two facets in a single higher-order 
construct is not warranted and that it may result in loss of predictive ability. Perseverance of effort was shown to predict achievement better than consistency of interest and it also showed incremental validity above conscientiousness when predicting academic achievement.

Grit is supposed to lead to success mostly by helping an individual to focus on a stable longterm goal (Duckworth \& Gross, 2014). Consistently, it has been found that grit predicts retention in various domains, such as marriage, workplace, education, and military training (EskreisWinkler, Shulman, Beal, \& Duckworth, 2014; Kelly, Matthews, \& Bartone, 2014). Other research suggests that the effect of grit on success might be mediated by deliberate practice. Gritty people may be more likely to exert effort and engage in relatively less enjoyable activities in order to achieve their goals (Duckworth et al., 2011).

Since grit is usually measured as a general construct and its effects should be specific to one's long-term goals, an important question is whether the association between grit and achievement would be stronger if the measure of grit focused specifically on the achievement domain (Duckworth \& Quinn, 2009). Several studies suggested domain-specificity of self-control (Duckworth \& Tsukayama, 2015; Tsukayama \& Duckworth, 2010; Tsukayama, Duckworth, \& Kim, 2012), which might be also present in grit. Supporting this notion, a recent study (Schmidt, Fleckenstein, Retelsdorf, Eskreis-Winkler, \& Möller, 2017) found that focusing a grit measure specifically on the context of school resulted in improved prediction of school grades. However, subject-specific measures did not predict grades in the subjects better than the measure of grit related to school.

In a similar vein, grit may predict achievement better for people who are highly motivated to succeed in a particular domain of achievement. Perseverance for long-term goals should have an effect on goal achievement only insofar that the goal is sufficiently important that a person is willing to exert effort to achieve it. Motivation may thus moderate the effect of grit on achievement. This is important because studies examining the association between grit and achievement often employ populations that are highly motivated to succeed, such as spelling bee participants or military cadets, which might result in a stronger effect of grit than would be observed in the whole population, where motivation varies more.

In the present two studies, we explored the association between grit and results in a scholastic aptitude test using large samples of Czech university applicants. Apart from estimating the strength of the association, we examined the possibility that measuring domain-specific grit may affect the predictive ability of grit. We therefore asked one group of participants to answer questions measuring grit specifically in relation to studying and we expected that this focused grit measure would predict the results better than a measure of general grit. On the other hand, we expected that asking about grit in relation to hobbies would lead to a weaker association between grit and the test results, given that the domain of hobbies is unrelated to performance in the test. We also explored whether motivation to get in a university moderates the association between grit and the results in the test. In a second study, we replicated findings of the first study. We also included a measure of conscientiousness and explored its relationship with grit as well as incremental validity of grit over conscientiousness in predicting the results of the scholastic aptitude test. 


\section{Study 1}

\section{Method $^{1}$}

\section{Participants}

The materials were administered as a part of a voluntary questionnaire given before administration of the General academic prerequisites (GAP) test used for university admissions in the Czech Republic. The questionnaire was given to 5427 people out of whom 3515 was given the version containing materials used in the present study. Out of the 3515 people, 2971 $(84.5 \%)$ filled the questionnaire. One hundred and sixty-two participants (5.5\%) failed to answer properly at least one of the questions in the grit measure used in the present study and were therefore excluded from analysis. The analysis was performed with data from the remaining 2809 participants, out of whom $57.7 \%$ were women, $40.6 \%$ were men, and the remaining $1.7 \%$ did not indicate their gender. Most of the participants were $18-21$ years old $\left(76.4 \% ; M d n_{\text {age }}=\right.$ 19.8, $\left.I Q R_{\text {age }}=2.6\right)$.

\section{Measures}

\section{Grit}

We measured grit using a 5-item grit scale used previously in The Penn Study of Young Adults (Duckworth, 2016; see also Park, Tsukayama, Goodwin, Patrick, \& Duckworth, 2017). The items were for example: "I finish whatever I begin." and "I stay committed to my goals." The full wording of the grit measure can be found on https://osf.io/nbp49/. The answer was given on a 5point scale ranging from "Not at all true" (1) to "Completely true" (5). The five items were introduced in one of three possible ways, which were randomized between participants. We asked participants to answer how true are the statements about them generally, in relation to studying, or in relation to their favorite hobby. We used averages of the five items in analysis. All three measures had reasonable internal consistency (see Table 1). Participants were more likely to endorse the statements than to disagree with them and all three measures had similar average scores (see Table 1). Internal consistency as well as means and variances were similar to those reported for a longer, 8-item Short Grit Scale (Duckworth \& Quinn, 2009).

\begin{tabular}{|r|r|r|r|}
\hline & General & Studying & Hobbies \\
\hline$N$ & 920 & 954 & 936 \\
\hline$M(S D)$ & $3.63(0.66)$ & $3.58(0.69)$ & $3.66(0.66)$ \\
\hline Cronbach's $\alpha$ & $0.76[0.73,0.79]$ & $0.79[0.76,0.81]$ & $0.76[0.73,0.78]$ \\
\hline
\end{tabular}

\footnotetext{
${ }^{1}$ Materials, data, and R scripts used for analysis for both studies can be found on https:/osf.io/fp8q9/. The study was not preregistered.
} 
Table 1: Descriptive statistics of the grit measures in Study 1. The table shows reliability and descriptive statistics for grit in the three studied domains. The numbers in brackets represent $95 \%$ confidence intervals.

\section{Test of general academic prerequisites}

The GAP test is used for university admissions at the undergraduate level by many Czech universities and it has similar structure as the Graduate record examination (GRE) used in tertiary education in the United States. It consists of four parts - verbal, quantitative, logic, and argumentation. The test has good reliability and it has been shown to correlate highly with the Scholastic aptitude test (SAT; $r=.76)$ and Raven's advanced progressive matrices $(r=.5$; https://osf.io/xaeu6/). Additional information about the test can be found in Bahník and Vranka (2017) and on https://osf.io/qr8r2/. The analysis was conducted with scores normalized by McCall transformation (McCall, 1939). The GAP test is administered in total 6 times per academic year and every person can sign up for any number of the administrations. The data used in the present study are from the fifth administration in the academic year of $2015 / 16{ }^{2}$

\section{Motivation}

Motivation to get in a university was measured by the question "How important is it for you to get in your preferred university?" with options ranging from "Not important" (1) to "Extremely important" (5).

\section{Results}

\section{Test of general academic prerequisites}

Measures of grit in all three domains correlated negatively with the results of the GAP test (see Figure 1 and Table 2). The negative association with the results of the GAP test was strongest for general grit, $r(918)=-.23,95 \% \mathrm{Cl}=[-.29,-.17], p<.001$, weaker for studying grit, $r(952)=-$ $.16,95 \% \mathrm{Cl}=[-.22,-.10], p<.001$, and weakest for hobbies grit, $r(934)=-.09,95 \% \mathrm{Cl}=[-.15$, .03], $p=.006$. The negative association between general grit and GAP test results was however not significantly stronger than the association between studying grit and GAP test results, $z=-$ $1.58, p=.11, \Delta r=-0.07,95 \% \mathrm{Cl}=[-0.16,0.02]$, but it was significantly more negative than the relationship between hobbies grit and GAP test results, $z=-3.12, p=.002, \Delta r=-0.14,95 \% \mathrm{Cl}=$ $[-0.23,-0.05]$. The difference between correlations of studying grit and hobbies grit with GAP test results was not significant, $z=-1.56, p=.12, \Delta r=-0.07,95 \% \mathrm{Cl}=[-0.16,0.02]$. The association between grit and GAP test results was negative even for participants who took the GAP test for the first time for general grit, $r(456)=-.24,95 \% \mathrm{Cl}=[-.32,-.15], p<.001$, studying grit, $r(497)=-.16,95 \% \mathrm{Cl}=[-.25,-.08], p<.001$, as well as for hobbies grit, $r(476)=-.12,95 \%$ $\mathrm{Cl}=[-.20,-.03], p=.01$.

\footnotetext{
${ }^{2}$ These data were also used for some analyses of effects of growth mindset in Bahník and Vranka (2017).
} 


\begin{tabular}{|c|c|c|c|c|c|}
\hline & GAP & General grit & Studying grit & Hobbies grit & Motivation \\
\hline \multicolumn{6}{|l|}{ GAP } \\
\hline General grit & -.23 & & & & \\
\hline Studying grit & -.16 & - & & & \\
\hline Hobbies grit & -.09 & - & - & & \\
\hline Motivation & -.05 & .20 & .28 & .22 & \\
\hline $\begin{array}{l}\text { No. of previous } \\
\text { administrations }\end{array}$ & .16 & -.14 & -.03 & .00 & .11 \\
\hline
\end{tabular}

Table 2: Correlations of the measures used in Study 1. The table shows Pearson correlation coefficients for the GAP test results, three grit measures, self-reported motivation to get in a university, and number of previous administrations attended by the participant. 

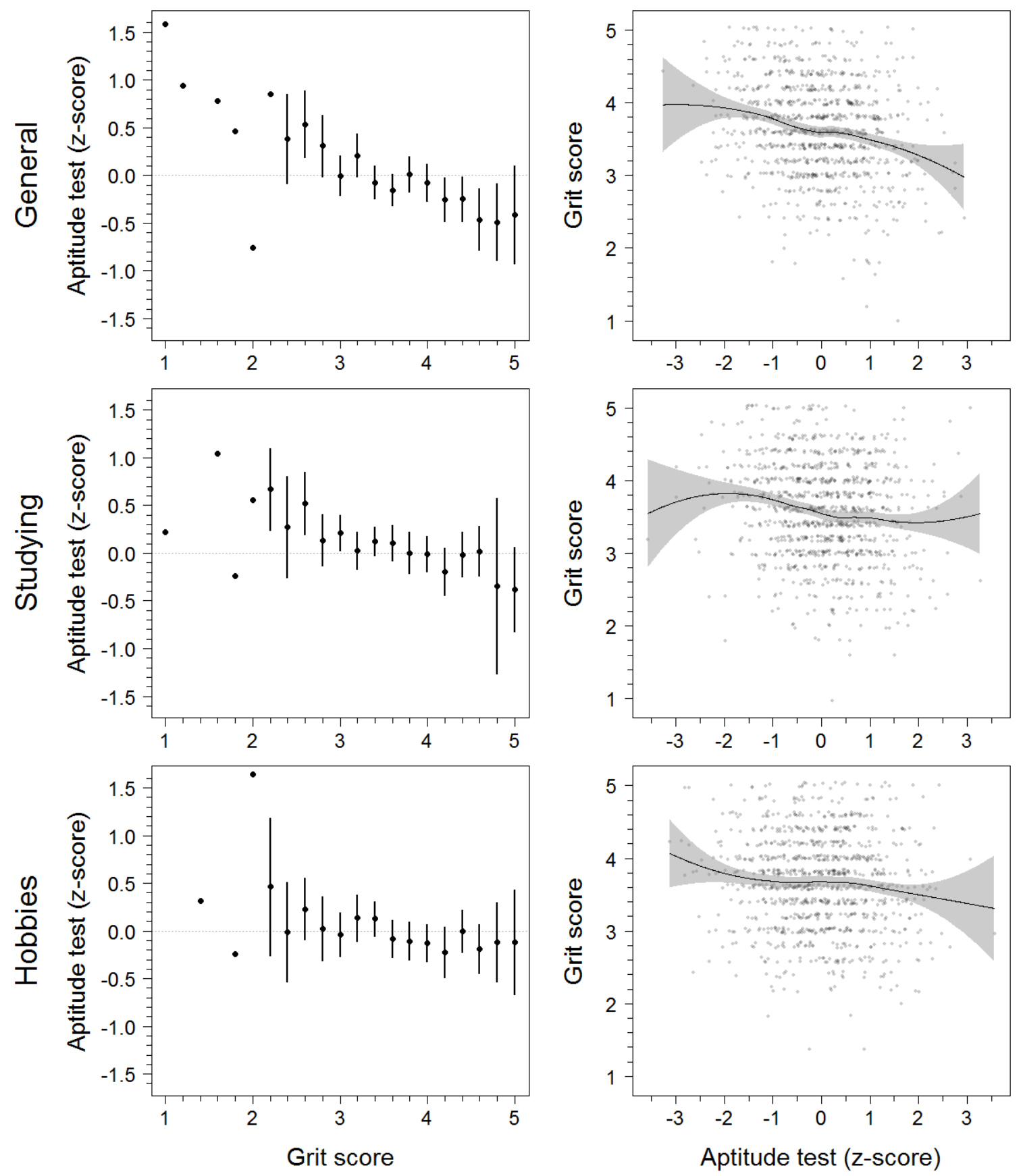

Figure 1: The association of results in the GAP test with grit in Study 1. The graphs on left show relationships between results in the GAP test and average scores in the grit scale. The error bars represent $95 \%$ confidence intervals of the means and are shown only for average grit scores with more than 10 observations. The graphs on right display the same relationship with switched axes. The black line shows a Loess curve. The shaded region shows a $95 \%$ confidence interval around the Loess curve. Note that we applied jitter to grit scores in the graphs on right.

It is possible to see from Figure 1 that the negative association held for participants within the whole range of abilities and within the whole range of the grit scale. Nevertheless, we tested the 
possibility of a break-point in the relationship between grit and GAP test results using Davies' test (Muggeo, 2008). The test did not show a significant change in the regression slope anywhere across the range of the GAP results for any of the grit measures, $p s>.30$. Furthermore, polynomial regression testing for a quadratic relationship of grit and GAP test results did not show a significant effect of the squared GAP test score for any of the grit domains, $p s>.21$.

\section{Motivation}

The question about motivation to get in one's preferred university was slightly negatively correlated with results of the GAP test, $r(2794)=-.04,95 \% \mathrm{Cl}=[-.08,-.01], p=.02$, but positively correlated with measures of grit in all three studied domains - general: $r(916)=.20$, $95 \% \mathrm{Cl}=[.13, .26], p<.001$; studying: $r(948)=.28,95 \% \mathrm{Cl}=[.22, .34], p<.001$; hobbies: $r(927)=.22,95 \% \mathrm{Cl}=[.16, .28], p<.001$. The correlation was stronger for studying grit than for general grit, $z=1.88, p=.06, \Delta r=0.08,95 \% \mathrm{Cl}=[-0.00,0.17]$, and for studying grit than for hobbies grit, $z=1.27, p=.20, \Delta r=0.05,95 \% \mathrm{Cl}=[-0.03,0.14]$, but the difference was not significant in either of the cases.

To test the moderating effect of motivation on the association between grit and GAP test results, we conducted a linear regression with a centered motivation rating, centered grit, and their interaction as predictors. The effect of grit remained negative for general grit, $t(914)=-7.01, p<$ $.001, b=-0.34,95 \% \mathrm{Cl}=[-0.43,-0.24]$, studying grit, $t(946)=-5.02, p<.001, b=-0.24,95 \% \mathrm{Cl}$ $=[-0.33,-0.14]$, as well as hobbies grit, $t(925)=-2.36, p=.02, b=-0.12,95 \% \mathrm{Cl}=[-0.22$, 0.02]. The interaction of motivation with grit was significant neither for general grit, $t(914)=0.98$, $p=.33, b=0.05,95 \% \mathrm{Cl}=[-0.05,0.14]$, studying grit, $t(946)=-1.81, p=.07, b=-0.09,95 \% \mathrm{Cl}$ $=[-0.19,0.01]$, nor for hobbies grit, $t(925)=0.60, p=.55, b=0.03,95 \% \mathrm{Cl}=[-0.08,0.15]$. While the interaction for studying grit could suggest that motivation might moderate the association between grit and results in the GAP test, the effect actually suggests that the effect of grit is even more negative for participants who are more motivated to get in a university. The effect of motivation was not significant in any of the regression analyses - general grit: $t(914)=$ $0.56, p=.57, b=0.02,95 \% \mathrm{Cl}=[-0.05,0.10]$; studying grit: $t(946)=0.13, p=.90, b=0.01$, $95 \% \mathrm{Cl}=[-0.07,0.08]$; and hobbies grit: $t(925)=-1.47, p=.14, b=-0.06,95 \% \mathrm{Cl}=[-0.14$, 0.02].

Taking the GAP test and preparing for it requires time and effort, which might be otherwise spent doing more pleasurable activities. We therefore examined whether participants who are more gritty are more likely to participate in a larger number of administrations of the test. However, the relationship of the number of GAP tests already taken with grit was negative for general grit, $r(918)=-.14,95 \% \mathrm{Cl}=[-.21,-.08], p<.001$, and there was no relationship with studying grit, $r(952)=-.03,95 \% \mathrm{Cl}=[-.10, .03], p=.33$, and hobbies grit, $r(934)=-.00,95 \% \mathrm{Cl}$ $=[-.07, .06], p=.89$. 


\section{Discussion}

The study showed a negative association between grit and results in a scholastic aptitude test. The negative association was present for measures of grit in all three domains - general, studying, and hobbies. While we expected that the grit measure focused on studying would have the strongest (positive) association with results in the GAP test, and the grit measure focusing on hobbies would have the weakest association, this was not the case. Although hobbies grit showed the weakest correlation with GAP test results, general grit showed the strongest correlation and all associations were in the direction opposite to our expectations.

We found that grit in all three domains was positively associated with motivation to get in a university. Given that people are more likely to exert effort to achieve goals they are highly motivated to attain, we expected that grit would be more positively related to the GAP test results for participants highly motivated to get in a university. If a gritty person was not motivated to get in a university, they would exert their effort to attain a different, more valuable goal (Duckworth \& Gross, 2014). However, we found no evidence for a moderating effect of motivation.

Because of space limitations, we were not able to use the full grit scale which had been previously validated (Duckworth et al., 2007; Duckworth \& Quinn, 2009); therefore, we used only a shorter 5 -item scale. It is possible to argue that this could have altered the measured construct. In particular, most of the items we used were related to perseverance of effort rather than the consistency of interest facet of grit. While this issue limits generalizability of the results, it is noteworthy that the perseverance of effort facet generally predicts achievement better than the consistency of interest facet (Credé et al., 2017).

Given that the data came from fifth administration of the test, it is possible that self-selection of participants could have obscured any possible positive association between grit and GAP test results. Participants with high grit could have had better results in previous administrations and therefore not participate in the later administration of the test from which we had the data available.

In the second study, we tried to overcome some of these limitations. We used a validated measure of grit, which contained four items measuring each facet of grit. We were therefore able to explore separately the association of perseverance of effort and consistency of interest with GAP test results. We also used data from the second administration of the GAP test within a given academic year, which was the first administration for most of the attending people. We thus mitigated the problem of self-selection that might have been present in Study 1. To measure the association between grit and other variables more precisely, we included only measures of studying and general grit in Study 2, which are of primary interest for the present paper. To examine the effect of grit on deliberate practice, we also included two questions asking about preparation for the test. We further included a question asking participants about their alternatives to studying a university, following the argument by Eskreis-Winkler, Gross, \& Duckworth (2016) which suggested that people with higher grit may value available alternatives to their current goals less than people with lower grit. Finally, we included a measure of 
conscientiousness in order to test the association of conscientiousness with grit as well as the association of conscientiousness with the GAP test results and its difference from the effect found for grit.

\section{Study 2}

\section{Method}

\section{Participants}

The materials were again administered as a part of a voluntary questionnaire given before administration of the GAP test. The questionnaire was given to 5104 people out of whom 2664 were given the version containing materials used in the present study. Out of the 2664 people, $2321(87.1 \%)$ filled the questionnaire. Two hundred and nine participants $(9.0 \%)$ failed to answer properly at least one of the questions in the grit measure used in the present study and were therefore excluded from analysis. The analysis was performed with data from the remaining 2111 participants, out of whom $61.0 \%$ were women, $38.4 \%$ were men, and the remaining $0.6 \%$ did not indicate their gender. Most of the participants were 18-21 years old $\left(95.9 \% ; M d n_{\text {age }}=19.1, I Q R_{\text {age }}=0.7\right)$.

\section{Measures}

\section{Grit}

We measured grit using the 8-item Short Grit Scale (Duckworth \& Quinn, 2009). In this study, we used only general and studying grit. The items related to studying were adjusted to be more relevant to the context of studying. For example, "New ideas and projects sometimes distract me from previous ones." was changed to "New areas of interest sometimes distract me from previous ones." The answers were provided on a 5-point Likert scale ranging from "Not like me at all" (1) to "Very much like me" (5). The full wording of the grit measure can be found on https://osf.io/nbp49/. Participants were randomly assigned to one of the scales. We used averages of the eight items in analysis after reversing the scores on items where agreement indicated negative grit, so that a higher score corresponded to higher grit in all items. Both measures had reasonable internal consistency (see Table 3).

\begin{tabular}{|r|r|r|r|}
\hline & General grit & Studying grit & Conscientiousness \\
\hline$N$ & 1053 & 1058 & 2059 \\
\hline$M(S D)$ & $3.29(0.55)$ & $3.30(0.55)$ & $3.50(0.60)$ \\
\hline Cronbach's $\alpha$ & $0.69[0.65,0.71]$ & $0.68[0.65,0.71]$ & $0.78[0.76,0.79]$ \\
\hline
\end{tabular}


Table 3: Descriptive statistics of the grit and conscientiousness measures in Study 2. The table shows reliability and descriptive statistics for the two measures of grit and conscientiousness. The numbers in square brackets represent $95 \%$ confidence intervals.

\section{Conscientiousness}

To measure conscientiousness, we used a 9-items scale from the Big Five Inventory (John \& Srivastava, 1999). The scale was introduced with "I see myself as someone who:" and listed nine characteristics such as "does a thorough job" and "tends to be lazy" which were evaluated on a 5-point scale ranging from "Not at all true" (1) to "Completely true" (5) and reverse-scored, so that a higher score corresponded to higher conscientiousness in all items.

\section{Test of general academic prerequisites}

The analysis was again conducted with scores normalized by McCall transformation (McCall, 1939). The data used in the present study were from the second administration in the academic year of 2016/17.

\section{Other measures}

We again included the same question as in Study 1 asking about motivation to get in a university. Furthermore, to assess the possibility of undervaluing alternatives suggested by Eskreis-Winkler et al. (2016), we asked our participants: "If you do not get in the university, your possible alternatives are:" and participants answered on a 4-point scale ranging from "Significantly worse" (1) to "Similarly good" (4). We also examined the amount of preparation for the test by asking participants to compare their preparation for the test with others on a 5-point scale ranging from "Much less" (1) to "Much more" (5) and by asking participants whether they attended a preparation course for the GAP test.

\section{Results}

\section{Test of general academic prerequisites}

The GAP test results again negatively correlated with both general grit, $r(1051)=-.17,95 \% \mathrm{Cl}=$ $[-.23,-.11], p<.001$, and studying grit, $r(1056)=-.11,95 \% \mathrm{Cl}=[-.17,-.05], p<.001$ (see Figure 2 and Table 4). While the correlation was again stronger for general grit than for studying grit, the difference was not significant, $z=-1.44, p=.15, \Delta r=-0.06,95 \% \mathrm{Cl}=[-0.14,0.02]$. When the two facets of grit were analyzed separately, perseverance of effort was significantly negatively related to the GAP test results for both general grit, $r(1051)=-.14,95 \% \mathrm{Cl}=[-.19$, $.08], p<.001$, and studying grit, $r(1056)=-.15,95 \% \mathrm{Cl}=[-.21,-.09], p<.001$, but consistency of interest was negatively related only for general grit, $r(1051)=-.14,95 \% \mathrm{Cl}=[-.20,-.08], p<$ .001 , and not for studying grit, $r(1056)=-.03,95 \% \mathrm{Cl}=[-.09, .03], p=.34$. The difference between the association of general and studying consistency of interest with the GAP test results was significant, $z=-2.48, p=.01, \Delta r=-0.11,95 \% \mathrm{Cl}=[-0.19,-0.02]$. 


\begin{tabular}{|c|c|c|c|c|c|c|c|c|c|c|c|}
\hline & 这 & 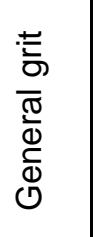 & 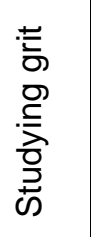 & 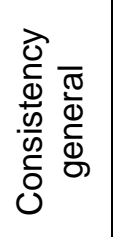 & 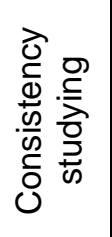 & 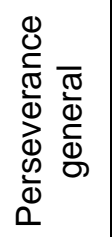 & 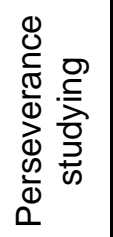 & 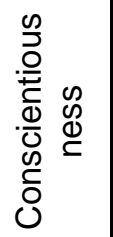 & 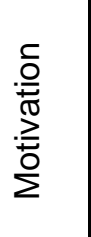 & 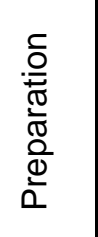 & 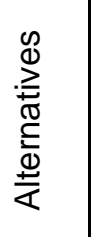 \\
\hline \multicolumn{12}{|l|}{ GAP } \\
\hline General grit & -.17 & & & & & & & & & & \\
\hline Studying grit & -.11 & - & & & & & & & & & \\
\hline $\begin{array}{l}\text { Consistency } \\
\text { general }\end{array}$ & -.14 & .80 & - & & & & & & & & \\
\hline $\begin{array}{l}\text { Consistency } \\
\text { studying }\end{array}$ & -.03 & - & .81 & - & & & & & & & \\
\hline $\begin{array}{l}\text { Perseverance } \\
\text { general }\end{array}$ & -.14 & .79 & - & .28 & - & & & & & & \\
\hline $\begin{array}{l}\text { Perseverance } \\
\text { studying }\end{array}$ & -.15 & - & .79 & - & .28 & - & & & & & \\
\hline $\begin{array}{l}\text { Conscientious } \\
\text { ness }\end{array}$ & -.12 & .59 & .62 & .38 & .42 & .56 & .58 & & & & \\
\hline Motivation & .02 & .15 & .24 & .05 & .14 & .19 & .25 & .17 & & & \\
\hline Preparation & -.03 & .23 & .15 & .16 & .08 & .21 & .17 & .20 & .22 & & \\
\hline Alternatives & -.14 & .04 & .12 & .02 & .10 & .05 & .10 & .08 & -.28 & -.05 & \\
\hline $\begin{array}{l}\text { Preparation } \\
\text { course }\end{array}$ & .04 & .08 & .05 & .08 & .03 & .05 & .05 & .02 & .10 & .24 & -.05 \\
\hline
\end{tabular}

Table 4: Correlations of the measures used in Study 2. The table shows Pearson correlation coefficients for the GAP test results; two grit measures and their facets; conscientiousness; selfreported measures of motivation to get in a university; relative amount of preparation for the test compared to others; quality of alternatives to studying at a university; and attendance of a preparation course. 

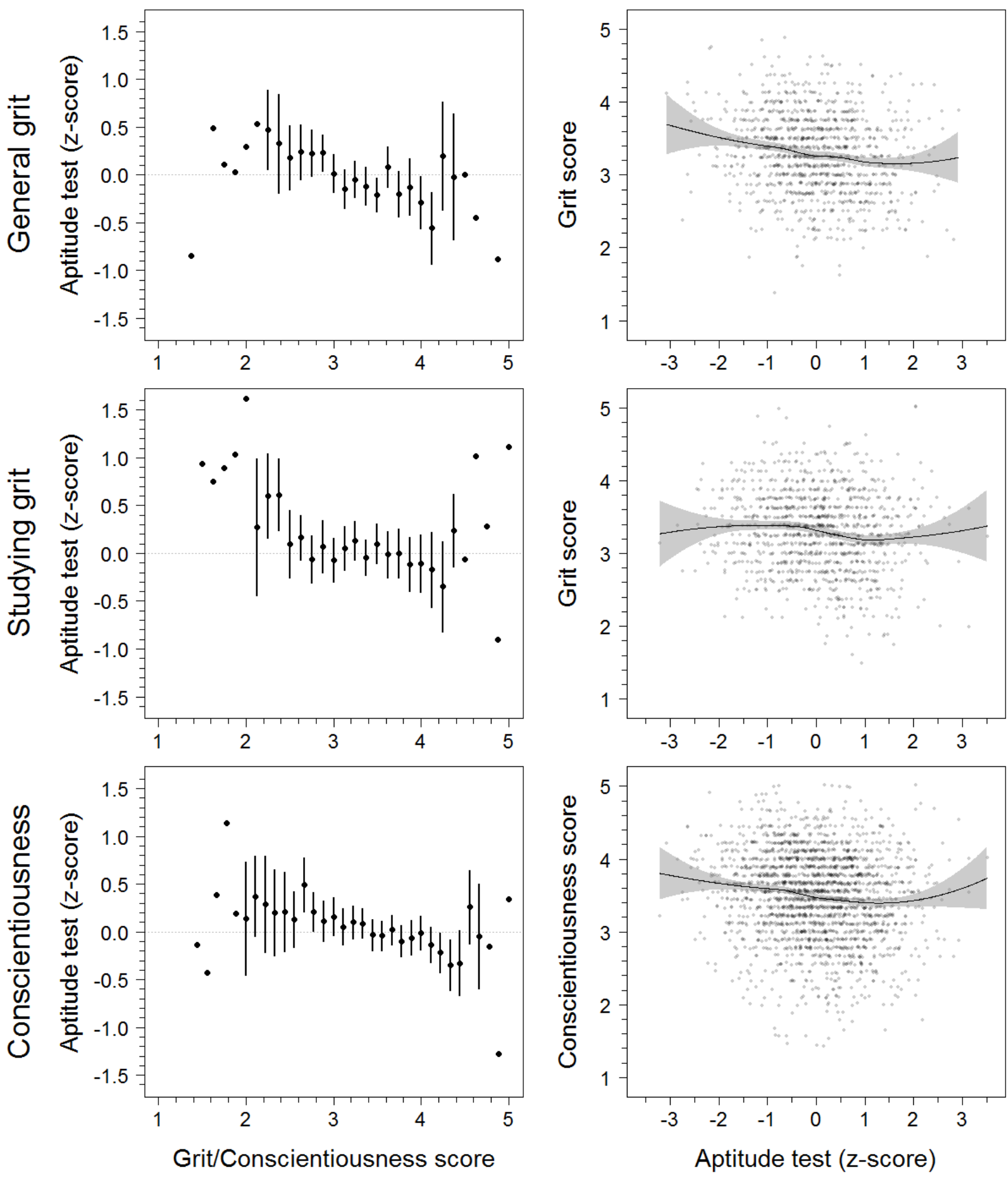

Figure 2: The association of results in the GAP test with grit and conscientiousness in Study 2. The graphs on left show relationships between results in the GAP test and average scores in grit and conscientiousness scales. The error bars represent $95 \%$ confidence intervals of the means and are shown only for average grit scores with more than 10 observations. Note that the average GAP test results for participants scoring general grit of $4.75\left(M_{4.75}=-2.17\right)$ is not shown here because it did not fall within displayed range of values. The graphs on right display the same relationship with switched axes. The black line shows a Loess curve. The 
shaded region shows a 95\% confidence interval around the Loess curve. Note that we applied jitter to grit and conscientiousness scores in the graphs on right.

Conscientiousness was also negatively correlated with GAP test results, $r(2057)=-.12,95 \% \mathrm{Cl}$ $=[-.17,-.08], p<.001$. Conscientiousness was similarly associated with general consistency of interest, $r(1021)=.38,95 \% \mathrm{Cl}=[.33, .43], p<.001$, as with studying consistency of interest, $r(1034)=.42,95 \% \mathrm{Cl}=[.37, .47], p<.001$. It was also related to perseverance of effort for both general grit, $r(1021)=.56,95 \% \mathrm{Cl}=[.52, .60], p<.001$, and studying grit, $r(1034)=.58,95 \% \mathrm{Cl}$ $=[.53, .62], p<.001$. The association with perseverance of effort was stronger than the association with consistency of interest for both general grit, $z=5.14, p<.001, \Delta r=0.18,95 \%$ $\mathrm{Cl}=[0.11,0.24]$, and studying grit, $z=4.81, p<.001, \Delta r=0.16,95 \% \mathrm{Cl}=[0.09,0.22]$.

The relationships between the three personality measures and the GAP test results were virtually unchanged when we used only data from the participants who took the test for the first time. The relationship was still negative for general grit, $r(662)=-.16,95 \% \mathrm{Cl}=[-.23,-.09], p<$ .001 , studying grit, $r(666)=-.13,95 \% \mathrm{Cl}=[-.20,-.05], p<.001$, as well as for conscientiousness, $r(1303)=-.13,95 \% \mathrm{Cl}=[-.19,-.08], p<.001$.

To explore the relationship between conscientiousness, facets of grit, and GAP test results, we built a structural equation model with conscientiousness, consistency of interest, and perseverance of effort as latent variables (Figure 3; Rosseel, 2012). The model showed that perseverance of effort correlated more strongly with conscientiousness than with consistency of interest. Surprisingly, even consistency of interest correlated more strongly with conscientiousness than with perseverance of effort; although the difference was smaller in this case. For general grit, the association with GAP test results was significant for consistency of interest, $z=-2.74, p=.006, r=-.11,95 \% \mathrm{Cl}=[-.19,-.03]$, but not for perseverance of effort, $z=$ $-1.81, p=.07, r=-.10,95 \% \mathrm{Cl}=[-.22, .01]$, or conscientiousness, $z=-0.11, p=.91, r=-.01$, $95 \% \mathrm{Cl}=[-.12, .11]$. For studying grit, the association with GAP test results was significant for perseverance of effort, $z=-2.93, p=.003, r=-.19,95 \% \mathrm{Cl}=[-.32,-.06]$, but not for consistency of interest, $z=-0.03, p=.98, r=-.00,95 \% \mathrm{Cl}=[-.09, .09]$, or conscientiousness, $z=0.46, p=$ $.65, r=.03,95 \% \mathrm{Cl}=[-.11, .17]$. The results suggest incremental validity of general consistency of interest and perseverance of effort related to studying over conscientiousness in predicting the GAP test results (Westfall \& Yarkoni, 2016). Grit thus seems to be useful for predicting failure in the test. The two models showed acceptable, but not great fit to the data - general grit: $\mathrm{CFI}=0.81, \mathrm{SRMR}=0.071, \mathrm{RMSEA}=0.079,90 \% \mathrm{Cl}=[0.075,0.084]$; studying grit: $\mathrm{CFI}=0.83$, $\mathrm{SRMR}=0.064, \mathrm{RMSEA}=0.075,90 \% \mathrm{Cl}=[0.071,0.080]$. We improved the model by including additional relationships between the variables indicated by modification indices, which resulted in a better fit of the model, but did not appreciably change the associations between conscientiousness, consistency of interest, perseverance of effort, and GAP test results (see https://osf.io/zkqga/). 

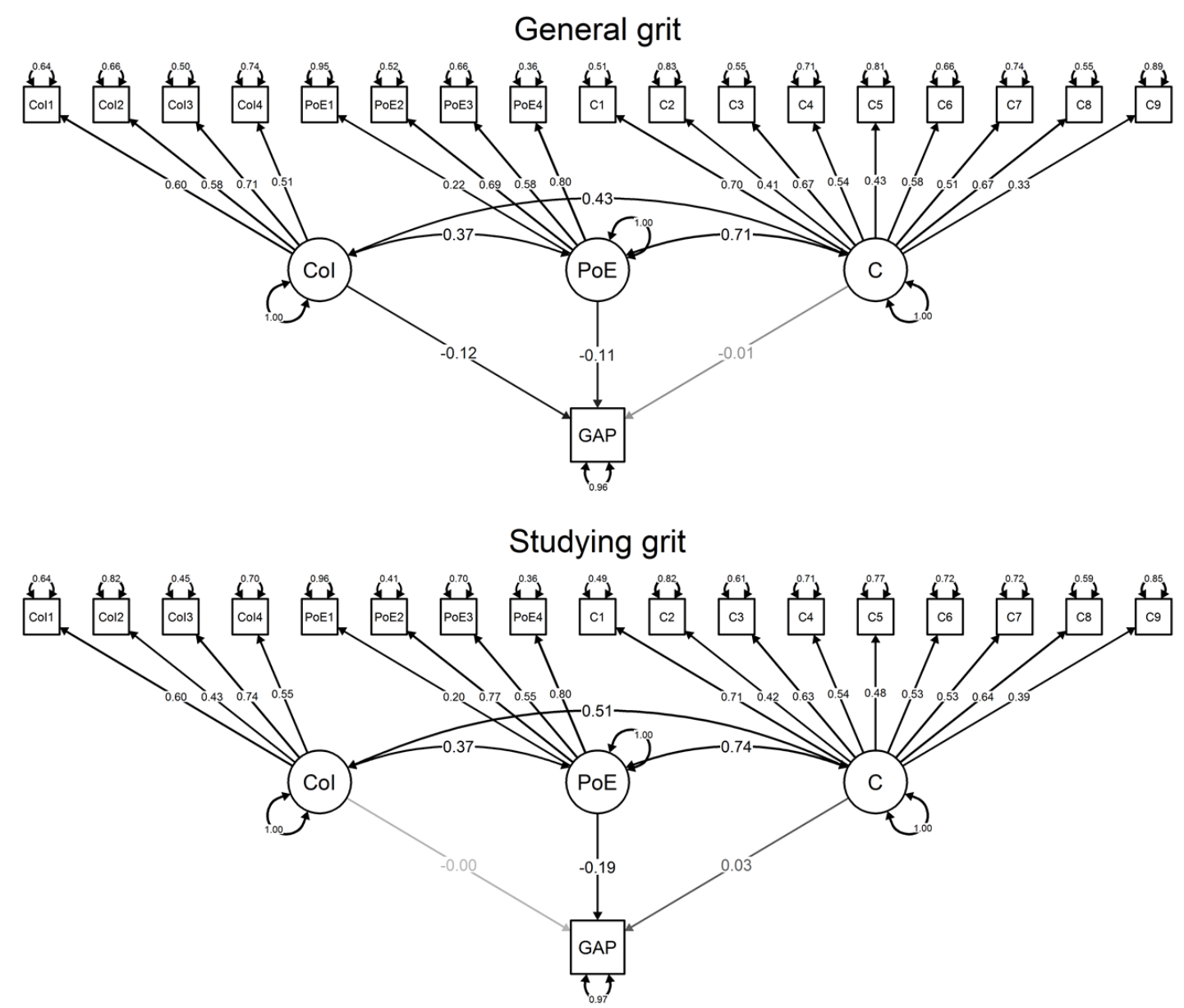

Figure 3: Structural equation models of relationships between GAP test results, conscientiousness, and facets of grit in Study 2. The figure displays standardized coefficients. Col - consistency of interest, PoE - perseverance of effort, C - Conscientiousness, GAP - GAP test results.

We again tested the possibility of a breakpoint in the relationship between GAP test results and the three personality measures using Davies' test. The test did not suggest a breakpoint for either of the grit measures, $p s>.59$. The Davies' test for conscientiousness was most consistent with a breakpoint at 1.6 for the GAP test measure, but the test was also not significant, $p=.10$. The breakpoint would suggest a negative relationship between conscientiousness and the GAP test results for values of the GAP test results lower than the breakpoint value, $b=-0.09,95 \% \mathrm{Cl}=[-0.12,-0.06]$, and positive relationship for values higher than the breakpoint value, $b=0.19,95 \% \mathrm{Cl}=[-0.09,0.48]$. Polynomial regression including squared centered GAP test results as a predictor did not suggest quadratic relationship of the GAP test results with either general grit, $t(1050)=1.27, p=.20, b=0.016,95 \% \mathrm{Cl}=[-0.009$, $0.040]$, or studying grit, $t(1055)=0.06, p=.95, b=0.001,95 \% \mathrm{Cl}=[-0.022,0.023]$. The analysis for conscientiousness was more consistent with a quadratic relationship, even though the effect was not appreciably stronger than for general grit, $t(2056)=1.92, p=.05, b=0.018$, $95 \% \mathrm{Cl}=[-0.000,0.036]$, and it was not significant. 


\section{Motivation}

The relationship between motivation and grit was positive for both grit measures (see Table 4) and it was again stronger for studying grit than for general grit, $z=2.05, p=.04, \Delta r=0.09,95 \%$ $\mathrm{Cl}=[0.00,0.17]$. The effect of grit was again negative even after inclusion of motivation in the analysis for both general grit, $t(1048)=-5.73, p<.001, b=-0.31,95 \% \mathrm{Cl}=[-0.42,-0.20]$, and studying grit, $t(1052)=-3.55, p<.001, b=-0.21,95 \% \mathrm{Cl}=[-0.33,-0.09]$. The interaction between grit and motivation was not significant for either general grit, $t(1048)=1.74, p=.08, b$ $=0.07,95 \% \mathrm{Cl}=[-0.01,0.14]$, or studying grit, $t(1052)=0.75, p=.46, b=0.03,95 \% \mathrm{Cl}=[-$ $0.05,0.12]$. The effect of motivation was not significant in regression with either general grit, $t(1048)=-0.67, p=.50, b=-0.04,95 \% \mathrm{Cl}=[-0.18,0.09]$, or studying grit, $t(1052)=0.17, p=$ $.86, b=0.01,95 \% \mathrm{Cl}=[-0.13,0.15]$.

Contrary to the suggestion of Eskreis-Winkler et al. (2016), we found that the self-reported quality of available alternatives was weakly positively correlated with both general grit, $r(1036)=$ $.05,95 \% \mathrm{Cl}=[-.01, .12], p=.08$, and studying grit, $r(1045)=.13,95 \% \mathrm{Cl}=[.07, .19], p<.001$, even though, only the latter effect was significant. When motivation and its interaction with grit were added in a regression model, the association of grit with available alternatives was still positive for both general, $t(1033)=3.10, p=.002, b=0.18,95 \% \mathrm{Cl}=[0.07,0.29]$, and studying grit, $t(1041)=6.81, p<.001, b=0.37,95 \% \mathrm{Cl}=[0.27,0.48]$. Motivation was negatively associated with the quality of available alternatives in both the model with general grit, $t(1033)=$ $-9.46, p<.001, b=-0.38,95 \% \mathrm{Cl}=[-0.46,-0.30]$, and studying grit, $t(1041)=-11.33, p<.001$, $b=-0.45,95 \% \mathrm{Cl}=[-0.52,-0.37]$, but the interaction of motivation and grit was not significant in either of the models, $p s>.58$.

Participants with higher general grit self-reported that they prepared more than others, $r(1030)=$ $.23,95 \% \mathrm{Cl}=[.18, .29], p<.001$, and an association in the same direction was found for studying grit, $r(1040)=.15,95 \% \mathrm{Cl}=[.09, .21], p<.001$. Surprisingly, the association was stronger for general grit than for studying grit, $z=1.94, p=.05, \Delta r=0.08,95 \% \mathrm{Cl}=[-0.00$, $0.16]$. The association between grit and preparation remained significant even when the results of the GAP test were included as a covariate and it was not moderated by the results of the GAP test. That is, the observed effect was not only a result of people with worse results preparing more.

A similar, even if weaker, effect was observed for attending a preparation course for the test. Participants with higher general grit were slightly more likely to report attendance of a preparation course, $r(1040)=.07,95 \% \mathrm{Cl}=[.01, .13], p=.02$. The effect was in the same direction for studying grit, but it was not significant, $r(1050)=.05,95 \% \mathrm{Cl}=[-.01, .11], p=.12$. The difference between the strength of association of the two grit measures with attendance of a preparation course was not significant, $z=0.56, p=.58, \Delta r=0.02,95 \% \mathrm{Cl}=[-0.06,0.11]$. The effect of general grit again remained significant even when the results of the GAP test were included in analysis and the association of studying grit with attendance of a preparation course was still nonsignificant. 
Finally, we analyzed whether motivation moderates the effect of grit on preparation. We did not find a significant interaction between motivation and either of the grit measures on self-reported preparation, $p s>.77$, or on attendance of a preparation course, $p s>.63$. The results did not support a moderating role of motivation on the effect of grit on preparation.

\section{Discussion}

The results of the second study replicated the results of Study 1 . We again found that both general grit and studying grit were negatively associated with GAP test results. Using a longer measure of grit, we were able to estimate the association with GAP test results separately for the two facets of grit. While perseverance of effort was negatively associated with GAP test results for both studying and general grit, a negative association was found for general consistency of interest but not for studying consistency of interest. Apart from grit, we also gave participants a measure of conscientiousness, which was highly correlated with grit and especially with the perseverance of effort facet of grit, as in previous research (Credé et al., 2017; Rimfeld, Kovas, Dale, \& Plomin, 2016). Similarly to grit, we found a negative association between GAP test results and conscientiousness.

As in Study 1, we asked participants about their motivation to get in a university. We replicated the result showing that participants with higher grit were more motivated to get in a university. We again did not observe an interaction between grit and motivation that would suggest a moderation of the effect of grit on GAP test results by motivation. Additionally, participants with higher grit reported that they prepared more in comparison to others and they were more likely to take a preparation course. The association between grit and motivation therefore did not hold only for self-reported motivation, but showed even when we asked about participants' behavior. While Eskreis-Winkler et al. (2016) argued that people with higher grit may undervalue alternatives to their goals, we did not find an effect that would be consistent with this suggestion. In fact, we found that participants with higher studying grit considered their alternatives to getting in a university as better than participants with lower studying grit.

\section{General discussion}

In two studies using large samples of university applicants, we found a negative association between grit and results of the GAP test, a scholastic aptitude test used for university admissions. The association was somewhat more negative when the measure of grit was general than when it focused specifically on studying or hobbies. However, the difference was significant only between correlations of GAP test results with general grit and with hobbies grit. In the second study, we also found that general consistency of interest was negatively associated with GAP test results, but consistency of interest related to studying was not. Altogether, the results support previous research (Schmidt et al., 2017) and suggest that focusing a measure of grit to a specific domain may tap into a slightly different part of the grit construct; although contrary to the previous study, predictive validity of the grit measure was not considerably improved. It is possible that the administration of the grit measure just before the 
university admission test might have made studying salient and therefore focused all participants on that domain.

Grit generally shows positive association with various outcomes in the educational domain (Credé et al., 2017), so the negative association between grit and GAP test results was surprising. A possible explanation of the result is that people with lower scholastic aptitude may compensate with higher grit. Students with higher scholastic aptitude might exert less effort in studying and this may in turn influence their grit (Göllner et al., 2017; Moutafi, Furnham, \& Crump, 2003; Moutafi, Furnham, \& Paltiel, 2004). This explanation would predict that the association is weaker or not present for students in lower grades, which could be tested in future studies.

Another explanation of the negative association between grit and GAP test results might be that participants had different goals for which they used their grit. The GAP test is administered during an academic year when high-school students are still attending classes and they may thus focus on finishing their studies rather than on the application to a university. Grit could thus lead to a higher focus on the goal to finish high school rather than on the goal to get in a university. Inconsistent with this explanation is the finding that participants with higher grit tended to be more motivated to get in a university and prepared more for the GAP test.

It is also possible that the negative association between grit and GAP test results was caused by a selection effect. For example, participants who have higher grit and higher scholastic aptitude could participate in the first administrations and thus be underrepresented in later administrations. While this possibility could explain the data from the first study, we had data for the second administration in a given academic year in the second study. Given that the second administration was the first one for most of the participants and that we found the same negative association between grit and GAP test results even for those who did not take the first administration, this selection effect does not explain the results well.

Another possible type of self-selection could be that people with low grit and low scholastic aptitude do not apply to a university (Murray, Johnson, McGue, \& lacono, 2014). Assuming that the effect of grit on the probability of applying to a university is stronger for people with lower scholastic aptitude, this type of self-selection would be especially pronounced in participants with low scores in the GAP test. The negative association between grit and GAP test results should be therefore stronger for participants with low GAP test scores and disappear at higher levels of GAP test scores. However, we did not find any evidence for the change of the relationship between grit and results in the GAP test for any level of scholastic aptitude.

Even though some of the findings are not in line with the described self-selection effects, it is still possible that the relative lack of participants who have both low grit and scholastic aptitude could be caused by selection during the course of education rather than self-selection by choice. It is, for example, possible that such students do not finish or even start secondary education and cannot therefore apply to a university. A related concern is that the sample of university applicants is likely to be above-average in scholastic aptitude. This range-restriction could have weakened or even reversed the association between grit and scholastic aptitude in our sample (Murray et al., 2014; Sackett \& Yang, 2000). 
Consistent with previous research (Duckworth et al., 2011), we found that participants with higher grit had stronger motivation to get in a university and prepared more for the test; however, the preparation did not result in a positive association between grit and GAP test results. Furthermore, we did not find a moderating effect of motivation on the association of grit and the test results. While some studies suggest that it is possible to improve one's results in tests similar to the GAP test by practice and coaching (Becker, 1990; Hausknecht, Halpert, Di Paolo, \& Moriarty Gerrard, 2007; Montgomery \& Lilly, 2012; Powers \& Rock, 1999), it can be argued that the GAP test mostly measures cognitive ability (Frey \& Detterman, 2004) and it is not possible to improve considerably one's results in the test. The negative association between grit and GAP test results found in our study would then be a result of the nature of the GAP test and grit could predict achievement better in domains where it is easier to improve one's result by practice and perseverance. Indeed, while grit generally shows positive association with various outcomes in the educational domain, it seems to have little or no relationship to cognitive ability (Credé et al., 2017).

As in other studies (Credé et al., 2017; Rimfeld et al., 2016), we found that grit, and especially the perseverance of effort facet of grit, was strongly related to conscientiousness. Furthermore, conscientiousness was associated with other variables similarly as grit. The results thus further support the notion that conscientiousness and grit measure a highly similar construct. Moreover, conscientiousness was more strongly related to both facets of grit than the two facets of grit to each other. This further questions justifiability of combining consistency of interest and perseverance of effort in a single higher-order construct (Credé et al., 2017; Tyumeneva, Kardanova, \& Kuzmina, 2017). As grit, conscientiousness has been previously found to predict academic achievement and to be independent on general cognitive abilities (Poropat, 2009). The explanation of the negative association of conscientiousness with GAP test results will be likely similar to the explanation of the negative association of grit and the test results, given the high similarity of the two constructs.

We believe that the present results are generalizable to other countries that use similar scholastic aptitude tests for university admissions. The results will not probably hold for aptitude testing in higher education (e.g., graduate studies), but the association between grit and scholastic aptitude might disappear or be reversed in earlier stages of education where selection and range-restriction effects play a smaller role. It is possible that the difference between domain-specific and general grit would be larger if the grit measure was better tailored to the studied context. Finally, the association between grit and success and their moderation by motivation might be more positive when the predicted result is less determined by relatively stable traits and more dependent on practice and effort.

In conclusion, we showed that grit was negatively correlated with scholastic aptitude, which suggests that it may not have much predictive utility in that context unless other traits are taken into account. It is possible that the effect of grit would reverse if the analysis controlled for intelligence and a future study may test for this possibility. The pattern of results did not change appreciably when the measure of grit focused specifically on studying, which suggests that grit may be largely consistent across domains. It is necessary to interpret the present results in light of possible selection and range-restriction effects, which could have reduced or even reversed 
the association between grit and scholastic aptitude. Future experimental studies might better elucidate whether grit is a promising target of educational interventions.

\section{Acknowledgements}

The work was supported by Internal Grant Agency of Faculty of Business Administration, University of Economics, Prague (IP300040). We would like to thank Scio company for the data from the National Comparative Exams GAP test used in the study. Both authors designed the study and prepared materials, Štěpán Bahník analyzed the data and wrote the report, Marek Vranka revised the manuscript and supervised data collection.

\section{References}

Bahník, Š., \& Vranka, M. (2017). Growth mindset is not associated with scholastic aptitude in a large sample of university applicants. Personality and Individual Differences, 117, 139143.

Becker, B. J. (1990). Coaching for the Scholastic Aptitude Test: Further synthesis and appraisal. Review of Educational Research, 60, 373-417.

Bowman, N. A., Hill, P. L., Denson, N., \& Bronkema, R. (2015). Keep on truckin' or stay the course? Exploring grit dimensions as differential predictors of educational achievement, satisfaction, and intentions. Social Psychological and Personality Science, 6, 639-645.

Credé, M., Tynan, M. C., \& Harms, P. D. (2017). Much Ado About Grit: A Meta-Analytic Synthesis of the Grit Literature. Journal of Personality and Social Psychology, 113, $492-$ 511.

Duckworth, A. (2016). Measures from Gates College Persistence Study. Retrieved from http://angeladuckworth.com/research/measures-from-gates-college-persistence-study/

Duckworth, A., \& Gross, J. J. (2014). Self-control and grit related but separable determinants of success. Current Directions in Psychological Science, 23, 319-325.

Duckworth, A. L., Kirby, T. A., Tsukayama, E., Berstein, H., \& Ericsson, K. A. (2011). Deliberate practice spells success why grittier competitors triumph at the national spelling bee. Social Psychological and Personality Science, 2, 174-181.

Duckworth, A. L., Peterson, C., Matthews, M. D., \& Kelly, D. R. (2007). Grit: perseverance and passion for long-term goals. Journal of Personality and Social Psychology, 92, 10871101.

Duckworth, A. L., \& Quinn, P. D. (2009). Development and validation of the Short Grit Scale (GRIT-S). Journal of Personality Assessment, 91, 166-174. 
Duckworth, A. L., \& Tsukayama, E. (2015). Domain-specificity in self-control. In C. Miller, R. M. Furr, A. Knobel, \& W. Fleeson (Eds.), Character: New directions from philosophy, psychology, and theology (pp. 393-411). New York, NY: Oxford University Press.

Eskreis-Winkler, L., Gross, J. J., \& Duckworth, A. L. (2016). Grit: Sustained self-regulation in the service of superordinate goals. In K. D. Vohs, \& R. F. Baumeister (Eds.), Handbook of self-regulation: Research, theory and applications (3rd ed.). New York, NY: Guilford

Eskreis-Winkler, L., Shulman, E. P., Beal, S. A., \& Duckworth, A. L. (2014). The grit effect: Predicting retention in the military, the workplace, school and marriage. Frontiers in Psychology, 5.

Frey, M. C., \& Detterman, D. K. (2004). Scholastic assessment or g? The relationship between the scholastic assessment test and general cognitive ability. Psychological science, 15(6), 373-378.

Göllner, R., Damian, R. I., Rose, N., Spengler, M., Trautwein, U., Nagengast, B., Roberts, B.W. (2017) Is Doing Your Homework Associated with Becoming More Conscientiousness? Journal of Research in Personality, doi: 10.1016/j.jrp.2017.08.007

Hausknecht, J. P., Halpert, J. A., Di Paolo, N. T., \& Moriarty Gerrard, M. O. (2007). Retesting in selection: A meta-analysis of coaching and practice effects for tests of cognitive ability. Journal of Applied Psychology, 92, 373-385.

John, O. P., \& Srivastava, S. (1999). The Big-Five trait taxonomy: History, measurement, and theoretical perspectives. In L. A. Pervin \& O. P. John (Eds.), Handbook of personality: Theory and research (Vol. 2, pp. 102-138). New York: Guilford Press.

Kelly, D. R., Matthews, M. D., \& Bartone, P. T. (2014). Grit and hardiness as predictors of performance among West Point cadets. Military Psychology, 26, 327-342.

McCall, W. A. (1939). Measurement: A Revision of How to Measure Education. New York, NY: Macmillan.

Montgomery, P., \& Lilly, J. (2012). Systematic reviews of the effects of preparatory courses on university entrance examinations in high school- age students. International Journal of Social Welfare, 21, 3-12.

Moutafi, J., Furnham, A., \& Crump, J. (2003). Demographic and personality predictors of intelligence: A study using the NEO personality inventory and the Myers-Briggs type indicator. European Journal of Personality, 17(1), 79-94.

Moutafi, J., Furnham, A., \& Paltiel, L. (2004). Why is conscientiousness negatively correlated with intelligence?. Personality and Individual Differences, 37(5), 1013-1022.

Muggeo, V. (2008) Segmented: an R package to fit regression models with broken-line relationships. $R$ News, $8,1: 20-25$. 
Murray, A. L., Johnson, W., McGue, M., \& lacono, W. G. (2014). How are conscientiousness and cognitive ability related to one another? A re-examination of the intelligence compensation hypothesis. Personality and Individual Differences, 70, 17-22.

Park, D., Tsukayama, E., Goodwin, G. P., Patrick, S., \& Duckworth, A. L. (2017). A tripartite taxonomy of character: Evidence for intrapersonal, interpersonal, and intellectual competencies in children. Contemporary Educational Psychology, 48, 16-27.

Poropat, A. E. (2009). A meta-analysis of the five-factor model of personality and academic performance. Psychological bulletin, 135, 322-338.

Powers, D. E., \& Rock, D. A. (1999). Effects of coaching on SAT I: Reasoning test scores. Journal of Educational Measurement, 36, 93-118.

Rimfeld, K., Kovas, Y., Dale, P. S., \& Plomin, R. (2016). True Grit and Genetics: Predicting Academic Achievement From Personality. Journal of Personality and Social Psychology, 111, 780-789.

Robertson-Kraft, C., \& Duckworth, A. L. (2014). True grit: Trait-level perseverance and passion for long-term goals predicts effectiveness and retention among novice teachers. Teachers College record, 116(3), 1-27.

Rosseel, Y. (2012). lavaan: An R Package for Structural Equation Modeling. Journal of Statistical Software, 48(2), 1-36.

Sackett, P. R., \& Yang, H. (2000). Correction for range restriction: An expanded typology. Journal of Applied Psychology, 85, 112-118.

Schmidt, F. T., Fleckenstein, J., Retelsdorf, J., Eskreis-Winkler, L., \& Möller, J. (2017). Measuring Grit. European Journal of Psychological Assessment, doi: 10.1027/10155759/a000407

Tsukayama, E., Duckworth, A. L., \& Kim, B. (2012). Resisting everything except temptation: Evidence and an explanation for domain-specific impulsivity. European Journal of Personality, 26, 318-334.

Tsukayama, E., Duckworth, A. L. (2010). Domain-specific temporal discounting and temptation. Judgment and Decision Making, 5, 72-82.

Tyumeneva, Y., Kardanova, E., \& Kuzmina, J. (2017). Grit: Two Related but Independent Constructs Instead of One. Evidence From Item Response Theory. European Journal of Psychological Assessment, doi: 10.1027/1015-5759/a000424

Westfall, J., \& Yarkoni, T. (2016). Statistically controlling for confounding constructs is harder than you think. PLOS ONE, 11(3), e0152719. 